\title{
Article \\ The Human Performance Impact on OEE in the Adoption of New Production Technologies
}

\author{
Sebastiano Di Luozzo *D, Georgiana Ramona Pop and Massimiliano Maria Schiraldi (D) \\ Department of Enterprise Engineering, “Tor Vergata” University of Rome, Via del Politecnico 1, \\ 00133 Roma, Italy; georgianaramona.pop@alumni.uniroma2.eu (G.R.P.); schiraldi@uniroma2.it (M.M.S.) \\ * Correspondence: sebastiano.di.luozzo@uniroma2.it
}

check for

updates

Citation: Di Luozzo, S.; Pop, G.R.;

Schiraldi, M.M. The Human

Performance Impact on OEE in the

Adoption of New Production

Technologies. Appl. Sci. 2021, 11, 8620.

https://doi.org/10.3390/

app11188620

Academic Editors:

Francesco Facchini, Salvatore Digiesi and Carlotta Mummolo

Received: 9 August 2021

Accepted: 14 September 2021

Published: 16 September 2021

Publisher's Note: MDPI stays neutral with regard to jurisdictional claims in published maps and institutional affiliations.

Copyright: (c) 2021 by the authors. Licensee MDPI, Basel, Switzerland. This article is an open access article distributed under the terms and conditions of the Creative Commons Attribution (CC BY) license (https:// creativecommons.org/licenses/by/ $4.0 /)$.
Featured Application: This research work proposes a framework for the evaluation of the initial adoption phase of new production technologies and its application to the introduction of a semi-automatic packaging machine in a relevant logistics company. The case study allowed the assessment of the machine ramp-up phase and provided valuable insights for reducing the length of this period by achieving a stable target production output. Moreover, it shows how the framework can be adopted, applied and interpreted for obtaining useful insights. Manufacturing systems in digital and interconnected industrial settings where human worker activity is required represents further potential applications of this paper.

Abstract: The initial adoption phase of new production technologies is the period between the first production run or technology reconfiguration and the achievement of a stable target output. This time frame is generally characterized by productivity unsteadiness, quality performance variability, and unexpected machine failures together with increasing production volumes due to the process setup and instability, which inevitably affects production output. In this context, human performance represents an additional source of variability and process instability that is dependent on the workers' productivity, learning curve and related training activities. Hence, to effectively assess the ramp-up phase of new production technologies, an appropriate evaluation of human performance is required. This paper proposes a comprehensive framework and criteria to perform a consistent assessment of the initial adoption phase of new production technologies by introducing two OEE measurement methodologies that distinguish between human performance, process configuration and technical features of the production technology. The proposed framework is then applied to and validated by a case study concerning the introduction of a semi-automatic packaging machine in a primary multinational company in the logistics industry. This case study shows the difference between the two OEE measures, along with the values interpretation and useful insights for achieving a stable production output.

Keywords: human performance; OEE; production technology; new technology adoption; manufacturing systems

\section{Introduction}

The ramp-up is defined as the period between the end of product development and full capacity production [1]. Following this definition, the ramp-up phase can be more precisely defined as the process of bringing a production system up to its required operational characteristics after it has been designed and built and before it is taken into full operation [2]. In this phase, the production process is often not fully understood and subject to errors, requiring adjustments that are costly for the company and which could lead to delays in introducing the product to the market [2]. Problems encountered during this phase include disturbances in process and product quality, a lack of reliable planning, unplanned capacity losses, and poor performance of suppliers [3]. Furthermore, 
the unpredictability of the system behavior generates process instability, since most of the operating conditions are unknown and are being applied for the first time. In this context, decisions concerning the planning and organization of the ramp-up become essentially complicated [4].

The goal of the ramp-up is to increase both the yield and the production rate in the shortest possible time [1]. However, at any time, there is a trade-off between the two mentioned parameters given that as production speed increases, the probability of encountering defects increases as well. Consequently, an increase in the number of reworks and of the work in process (WIP) is faced. In addition, according to Little's law, the average waiting time also increases, as well as the time between the occurrence of the problems upstream of the process and their detection in the downstream verification stations: as soon as problems are identified, there is a faultier WIP in circulation to be reworked [1]. Hence, this trade-off should be considered carefully to achieve effective management of the ramp-up period. Indeed, during the production start-up, several unanticipated problems may occur, which should be managed carefully so as not to impact either other business processes or the customer experience. Process errors should be reduced through constant attention to the learning and observation of the interaction between the elements of the production system.

The production ramp-up phase can be considered a learning process that could be reflected in better usage of the equipment, in the continuous improvement of product quality, and in the reduction of labor requirements [5]. The length of this period can be measured either as "ramp-up time" or as "time to volume", and it is characterized by a gradual increase in the output production rate as well as an improvement in the recorded quality rate [6]. Moreover, the adoption phase of new production technologies includes a learning phase for both production managers and operators [7]. However, most of the complexity is managed by the operators, so the effectiveness of the ramp-up largely depends on their experience and knowledge [2]. Hence, human performance represents an additional source of variability that dramatically impacts the ramp-up phase and that should be properly assessed. Though the key role of the human factor is recognized in the scientific literature, it seems that there is a lack of contributions including this element in the ramp-up phase evaluation, often due to the absence of available data for its assessment.

In this context, digitalization and Industry 4.0 can offer support during the adoption phase of new production technologies, since they enable companies to analyze large amounts of real-time data, improving strategic and operational decision-making activities [8]. The key element that characterizes this new industrial phase is the profound change in the connectivity of production systems due to the integration of information and communications technology (ICT), Internet of Things (IoT) and machinery in cyber-physical systems (CPS). The ramp-up phase can thus benefit from these technological advancements since they enable a more punctual, immediate and precise performance evaluation, which can be used to effectively drive operations. Moreover, the production systems interconnectivity and the improved man-machine interaction allow key data to be recorded, collected and analyzed to distinguish between machine and human performances.

As a consequence of the previous considerations, new research works and practical applications concerning the ramp-up phase should consider opportunities to design comprehensive methods for its effective evaluation. Indeed, the growing usage of digital information and communication technologies opens new opportunities for productivity management in manufacturing companies, with an estimated average increase in productivity of $32 \%$ by 2025 due to digitalization [9]. This increase in productivity can be linked to the way digitalization changes the handling of data and information by offering new and extended ways for collecting, transferring, evaluating, and exploiting information, all of which are opportunities that allow increases in effectiveness and efficiency [10].

In addition, as a result of the exploitation of the Industry 4.0-enabling technologies, an evolution of tasks to be performed by operators is taking place. Indeed, the operator should not only perform cooperative work with robots, but also machine-assisted work by means 
of CPS systems and advanced man-machine interaction technologies and adaptive automation towards human-automation symbiosis work [11-13]. Considering this background, the contribution of Alharbi (2020) [14] discusses the knowledge and skills that operators should have in an Industry 4.0 manufacturing context and provides valuable insights for managing this technological revolution. Following the same path, Fantini et al. (2020) [15] propose a human-centric model to evaluate several work configurations where human activities are integrated within cyber-physical systems, along with relevant human-driven performance indicators. The role of the "Operator 4.0 " is also analysed in the paper of Silvestri et al. (2020) [16], which discusses its required tasks in relation to maintenance activities. Furthermore, Industry 4.0 provides an improvement in operator training operations through the usage of virtual reality-based tools by reducing the total time spent for practical training [17].

In light of the previous considerations, this paper aims to propose a comprehensive framework to evaluate the initial adoption phase of new production technologies in a digital and interconnected industrial environment. Two "overall equipment effectiveness" (OEE) measurement methodologies that distinguish between human performance, process configuration and technical features of the production technology are here introduced and discussed. The framework allows for the evaluation and determination of the conditions under which the transition from the ramp-up phase to the fully operational state is achieved. Hence, this contribution provides valuable insights for the reduction of the overall time required by allowing a stable production output to be achieved. In addition, it can also be adopted to perform an effective and more precise production and workforce capacity planning ahead of the conclusion of the ramp-up period.

The paper also reports an application of the proposed framework to a case study related to the introduction of a semi-automatic packaging machine in a primary multinational company in the logistics industry. This allowed the methodology to be tested and validated. Furthermore, a wide literature review on research works concerning the ramp-up phase is provided to determine which relevant criteria can be applied for the assessment of the initial adoption phase of new production technologies. Thus, the proposed framework can be adopted to reduce the overall transition period from the ramp-up phase to the fully operational state of the machine; to perform an effective and precise production planning before the ramp-up phase is concluded; and to obtain a reference of the different research works and methodologies that can be applied to the initial adoption phase of new production technologies.

According to the previous considerations, the novelty of this contribution follows. To our knowledge no research work has introduced a framework able to distinguish between human performance, process configuration and technical features of the production technology. For this reason, the scientific literature is missing a methodology capable of helping manufacturing organizations, researchers and practitioners achieve effective management of the ramp-up period following the introduction of new production technologies. Our paper directly addresses this lack and also provides a case study showing the framework application.

The rest of the paper is organized as follows. Section 2 provides the scientific background on the human and technical factors to be considered in the ramp-up phase and defines the applicable criteria to the initial adoption phase of new production technologies. Section 3 introduces the proposed framework, and Section 4 describes the case study. Finally, Section 5 presents the conclusions and further potential developments of this research work.

\section{Literature Review}

During the adoption phase of new production technologies, disturbances affecting both productivity and product quality are encountered more frequently due to system instability, reconfigurations or process changes. The main challenges to be faced concern the adaptation of the capacity of the production system, the reliability of the production 
equipment to meet the target production rate, the understanding of the new process behavior and the increase in product quality [6]. The production process is adjusted until it becomes sufficiently stable and the output reaches a target level, reducing disturbances to a minimum. The time required for this phase is highly dependent on the complexity of the system and the planners' ability to make good decisions based on their experience. The ramp-up is a man-machine coordination process that varies in each instance based on the experience of the staff and the complexity of the system, thus being highly unpredictable [2].

Colledani et al. (2018) [6] and Terwiesch and Bohn (2001) [1] offer a description of the types of production ramp-up: launch of new products, start of a new process, and reconfiguration of an existing process. The differences between the various types can be retrieved in the complexity of the studied variables and in the variation of the life cycle of new products or new technologies. Considering the product launch, the production start-up begins with the approval of pre-series production, which is described as the development of a large number of prototypes mainly used to teach workers about new processes and to identify and resolve errors [6]. Differently, when dealing with new processes, such as the introduction of new equipment, the system assembly is required before the production start, following the approval and correction of the functions and parts of the system, where necessary [18].

For the measurement of the production rate, the production throughput (TH) is considered one of the most important parameters of a production system [19]. The three main factors that directly impact TH are: availability affected by downtime events, low performance due to slow operations, and product quality affected by defects [19]. Colledani et al. (2018) [6] discuss the methodology to evaluate the actual lost TH during the ramp-up phase following a system reconfiguration, where the actual $\mathrm{TH}$ is given by the production of compliant products. In their contributions, the authors define the ramp-up of a process as the time interval between the production of the first article after a system reconfiguration and the stable production of articles at a target TH. The loss of TH occurs and is accentuated with each reconfiguration of the system because the actual production rate during the reconfiguration period is equal to zero, and a new ramp-up period is observed each time the production is restarted. The authors also classify the causes of TH loss into two categories: internal, which originates within the studied system and includes both human and technological factors; and external, which originates outside the system and may have an indirect effect on the behavior of the system [6].

From this consideration, a literature background on the human factors and technological factors impacting the initial adoption phase of new production technologies is provided, as well as an assessment of the relevant criteria for its evaluation. Indeed, after discussing the human and technological factors, the applicability of each criterion to the ramp-up phase is assessed and described.

\subsection{Human Factors in the Initial Adoption Phase of New Production Technologies}

The goal of ramp-up phase management is to reduce or control uncertainty and instability of the start-up. In this context, the process knowledge and the learning of employees become key points to reach this objective. Learning leads to a better understanding of production processes and improves performance in terms of quality, time and cost [20].

Argote and Miron-Spektor (2011) [20] highlight the importance of favoring the phenomenon of spillover between consecutive ramp-ups and between individuals to improve the performance of the system and to accelerate learning. In the knowledge transfer between consecutive ramp-ups, the authors make a distinction between explicit knowledge, given by precise and codified explanations, and tacit knowledge, given by subtle knowledge that is related to a person and is based on experiences and insights. Companies can choose different ways for knowledge transfer to occur in order to equip workers with the required skills during the ramp-up phase of production: the transfer of explicit knowledge is simple and easy-given that this type of information is generally written-while, on the contrary, the transfer of tacit knowledge is more difficult because it is individual 
and difficult to code [21]. Usually, the transfer of tacit knowledge can occur through observation and imitation of others-therefore, social interaction-when a new activity is performed [21]. This phenomenon is even more relevant since human operators involved in the ramp-up process may experience a slower learning curve than planned, causing an extension of the processing time, excessive corrective maintenance time, or inaccurate inspection operations [6].

Schmitt et al. (2018) [18] focus the attention on the role played by the organizational structure for learning and for production start-up management. Indeed, the authors observe that several departments are involved in this phase whose influence and importance vary in relation to its progress. Generally, a ramp-up manager is identified who has the purpose of guaranteeing continuous process management and participating during the various phases. Moreover, the authors identified two main organizational types:

1. Non-dedicated operators: the knowledge and skills of the staff can be shared between the functional departments, and the employees are involved in the phase of ramp-up in addition to regular work. The benefit deriving from this structure is the consistently high staff utilization rate, but problems could be generated if conflicts occur between the regular organization and the one dedicated to the project;

2. Dedicated operators: employees belong to the regular departments, though they are released from the job routine and are completely dedicated to the ramp-up phase during the project lifespan. This leads to a better direct focus on the implementation of the project and a greater effect of learning. However, as a disadvantage, there is a rate of use of human resources which is lower than the first approach.

In the same context, Scholz-Reiter et al. (2007) [22] propose to use dedicated teams for the launch of new products; these teams are to be used during the modification of the technical characteristics of the product. This would avoid criticalities due to late implementation of different types of changes, which can cause problems in terms of target values imposed for timing, quality and cost. To counteract possible inefficiencies, the authors proposed the presence of two dedicated teams: one short-term team created to solve specific technical problems, and one long-term team dedicated to preventive actions related to the new process. With this approach, knowledge would be preserved between consequent ramp-ups.

Another important aspect during production start-up management is the training and learning of operators. While switching from low volume to high volume production, workers are assumed to have improved their knowledge about the production process that was not initially well understood [1], leading to increased productivity over time due to repetitive execution of activities by employees, familiarization with the production process and organizational-technological changes [3]. Terwiesch and Bohn (2001) [1] model the learning process in the form of experiments performed on the system during the ramp-up phase, collecting specific information on resource behavior and highlighting the criticality of learning.

Moreover, Industry 4.0 provides help for training operations using virtual reality (VR) [17]. By using virtual simulation and training (VISTRA), representing a system that simulates the manufacturing environment, it was observed that operators can speed up the ramp-up period by reducing the time spent in practical training in the real environment and showing the most critical operations in the learning phase. Hoedt et al. (2017) [23] show that the effect of virtual training during a virtual assembly experiment guarantees, on average, $72 \%$ of the learning effect by performing all activities for the first time in the real context. The effect of the actual training was a reduction in assembly time by $27 \%$, while virtual training induces a $20 \%$ improvement.

Several scientific contributions have also described and modeled the training progress of workers using learning curves. In the production and operations management field, the learning curves describe the improvement in worker performance due to repetition of activities or experience, and, therefore, they are of fundamental importance in the managerial decision-making process. The phenomenon of human training is relevant in 
labor-intensive manufacturing companies, especially where the labor cost is expensive [5]. Learning curves can be applied to define more accurate job standards, track realistic production goals, forecast the available working time of a process, and forecast production output and compliant units.

Learning by doing is a natural phenomenon that improves human performance, and it leads to a reduction in the time required to perform an activity for each repetition [24]. In 1936, Wright noted that when doubling the produced volumes, the unit production time was reduced by a constant percentage [25]. Based on this consideration, he defined the learning curve that can be used in operations management as a supporting function in the planning of the volumes to be processed. The curve can be used to derive the time spent by employees to learn a new activity and, consequently, plan the workforce during full production. In the same context, Ball et al. (2011) [24] affirm that the opposite phenomenon to learning, namely the tendency to forget, must also be considered in formation. In the field of industrial engineering, the common assumption is that if the worker interrupts the execution of activities for a certain period, then the performance of the worker deteriorates up to when a new production session begins [24]. The time elapsed between the training of the operators and their insertion in the process must be minimal to avoid reducing the performance of the employee. Neglecting this key factor in human resource planning could lead to under sizing the required staff to produce a certain target volume.

In addition, some scientific contributions have attempted to determine performance indicators for the assessment of industrial operators. For instance, Manca et al. (2012) [26] assess human factor performances during the operator training period through the "Analytic Hierarchy Process" (AHP) methodology. Other research works discuss the evolution of operations roles with the impact of Industry 4.0 by focusing on the interconnection between new technologies and humans, and on the increase in compatibility, effectiveness, safety, human well-being and quality of life [27,28]. However, there is no performance assessment methodology that integrates inefficiencies due to human factors in the main "Key Performance Indicators" (KPIs) adopted for the process evaluation. Therefore, it seems that the scientific literature is missing the opportunity to integrate the digitalization and Industry 4.0 data collection capability with relevant performance assessment methodologies, with the result being an inability to distinguish between the human factor and equipment performances.

\subsection{Technical Factors in the Initial Adoption Phase of New Production Technologies}

The ramp-up phase is characterized by extreme instability resulting from various changes that are implemented in the process, products or equipment, which can be both intentional and unintentional. Consequently, the complexity of this period can increase significantly, leading to unpredictability and uncontrollability of the entire system, given that each adjustment of the system and of its parameters could lead to a decrease in production quantity. Therefore, the effectiveness of the ramp-up phase can be hardly predicted, and it is unlikely to reach the set targets of time, cost and quality [29].

One of the most relevant elements in the initial adoption phase of new production technologies is related to the supplier capabilities. Indeed, approximately $37 \%$ of production line disruptions during the ramp-up period are related to problems originating from the suppliers [1]. Differently, Wlazlak and Hilletofth (2019) [30] propose a model for original equipment manufacturer (OEM) supplier integration during ramp-up through a two-way communication about changes, costs, specification, resolution of technical problems and investments in new manufacturing technologies [30]. Colledani et al. (2018) [6] identify the behavior of the equipment among the causes of TH loss during the initial adoption phase of new technologies. Nominal conditions provided by the supplier of the technology are considered in the design phase of the system; however, during the integration of the equipment into the real system, more failure modes may emerge than those indicated by the supplier. Therefore, the greater the effort devoted to the design and planning of the ramp-up phase, the more efficient it will be in terms of time and cost [24]. 
On a different aspect, several scientific contributions discuss methodologies and approaches to optimize ramp-up conditions and equipment management. Klocke et al. (2016) [31] propose a model for the selection of machinery and equipment to obtain favorable conditions during the production start-up. The authors defined a target system for the evaluation of different technologies or production systems in which they considered parameters such as time to market and time to volume. However, the authors provide only a limited overview on the business processes without considering the whole supply chain. Burggraf et al. (2016) [32] propose the use of the modular approach to counter the spread of the ramp-up effects in the production system, to reduce the complexity of the system, and to decouple the various modules. The limitation of this research lies in the lack of modular structures in already existing companies; therefore, the approach becomes not applicable in most industrial contexts. Colledani et al. (2018) [6] indicate the use of continuous improvement approaches to identify and remove disturbances affecting the behavior of the equipment, breakdowns of machinery and the integration of resources into the system with a perspective oriented to production. The study could be integrated with a methodology for reducing the variability of the TH obtained during the ramp-up phase, given that the performance improvement of a system could be partially hidden and difficult to trace in a system characterized by high variability. Finally, Schuh et al. (2015) [33] introduce a framework for ramp-up process management based on system complexity, while Kukulies and Schmitt (2018) [34] develop a model to stabilize production output by modeling uncertainties in the product design phase.

In conclusion, though the technological factors of the ramp-up are largely studied in the scientific literature, they are never integrated with human factors in a comprehensive framework to evaluate the ramp-up period of new production technologies. Indeed, the ramp-up is a learning process characterized by human errors and learning by doing, and there is no methodology for the evaluation of its performances that takes into consideration both source of inefficiencies.

In this context, the overall equipment effectiveness (OEE) is currently one of the most relevant frameworks to evaluate the effectiveness of individual equipment and integrated production systems [35]. OEE is an indicator that supports management to determine production capacity, reduce production losses and evaluate new equipment investments, but the traditional evaluation method does not explicitly consider the human factor. Hence, through exploiting the potential of digitalization and Industry 4.0, this paper provides a comprehensive framework for analyzing the initial adoption phase of new production technologies by considering the human aspects that impact the ramp-up period.

\subsection{Summary of the Criteria and Applicability to the Initial Adoption Phase of New Production Technologies}

From the previous considerations, even though a great effort has been made towards the discussion of the main factors that impact the initial adoption phase of new production technologies, it seems that a framework for obtaining a comprehensive evaluation of this phase is missing.

Differently, several scientific contributions proposed models and criteria for the rampup phase of new products, new processes and following a reconfiguration of the system. For this reason, a review of these criteria has been performed to identify their applicability to the specific ramp-up phase of new production technologies. The results of this assessment are shown as in Table 1 which reports all the criteria, the research work they have been introduced in, the specific type of ramp-up they are referred to, and the evaluation of their applicability to the initial adoption phase of new production technologies. 
Table 1. Applicability of ramp-up criteria to the initial adoption phase of new production technologies.

\begin{tabular}{|c|c|c|c|c|}
\hline$\#$ & Criterion & Reference & Type of Ramp-Up & $\begin{array}{l}\text { Applicability during the Initial Adoption } \\
\text { Phase of New Production Technologies }\end{array}$ \\
\hline 1 & $\begin{array}{l}\text { Measurement of the ramp-up period: } \\
\text { ramp-up time or time to volume }\end{array}$ & [6] & $\begin{array}{c}\text { New process or } \\
\text { system reconfiguration or launch of } \\
\text { new products }\end{array}$ & $\begin{array}{l}\text { Yes, time to volume can also be adopted } \\
\text { for new production technology evaluation }\end{array}$ \\
\hline 2 & $\begin{array}{l}\text { Plan for a gradual increase in volume: } \\
\text { pre-series production, low output volume, } \\
\text { regular start of the production, maximum } \\
\text { productivity level }\end{array}$ & {$[6]$} & Launch of new products & $\begin{array}{l}\text { Yes, to plan a gradual increase of } \\
\text { production of new machineries }\end{array}$ \\
\hline 3 & $\begin{array}{l}\text { Test plan and start of production for new } \\
\text { machineries: preliminary acceptance of the } \\
\text { project, final acceptance, transit in the stage } \\
\text { of use, increase in output volume, target } \\
\text { production level }\end{array}$ & [18] & $\begin{array}{l}\text { New technology } \\
\text { or new process }\end{array}$ & $\begin{array}{l}\text { Yes, to ensure that the technology } \\
\text { meets the company's quality } \\
\text { and safety standards }\end{array}$ \\
\hline 4 & $\begin{array}{l}\text { Measurement of actual and lost TH } \\
\text { and reduction of its variability }\end{array}$ & [6] & System reconfiguration & $\begin{array}{l}\text { Yes, to identify the causes } \\
\text { of production inefficiencies }\end{array}$ \\
\hline 5 & $\begin{array}{l}\text { Identification of the internal and external } \\
\text { causes that lead to a loss of TH }\end{array}$ & {$[6]$} & System reconfiguration & $\begin{array}{c}\text { Yes, considering the behavior of the } \\
\text { equipment, human errors and any causes of } \\
\text { misalignment between what was designed and what } \\
\text { occurred in reality }\end{array}$ \\
\hline 6 & $\begin{array}{l}\text { Selection of machineries and equipment } \\
\text { to obtain favorable conditions for ramp-up } \\
\text { and decrease the loss of TH }\end{array}$ & [31] & $\begin{array}{l}\text { New technology or } \\
\text { system reconfiguration }\end{array}$ & $\begin{array}{l}\text { Yes, by selecting a machinery } \\
\text { that can be quickly integrated }\end{array}$ \\
\hline 7 & $\begin{array}{l}\text { Macro-strategies for TH reduction: } \\
\text { anticipation of disturbances in the } \\
\text { production phase, data collection and } \\
\text { analysis for continuous improvement }\end{array}$ & {$[6]$} & System reconfiguration & $\begin{array}{l}\text { Yes, through cooperation between the } \\
\text { machinery supplier and the operations team }\end{array}$ \\
\hline 8 & $\begin{array}{l}\text { Reduction of the ramp-up time through } \\
\text { the delay of detailed system descriptions }\end{array}$ & {$[6]$} & System reconfiguration & $\begin{array}{l}\text { No, as any changes made while } \\
\text { production has started could negatively } \\
\text { impact the entire process }\end{array}$ \\
\hline
\end{tabular}


Table 1. Cont.

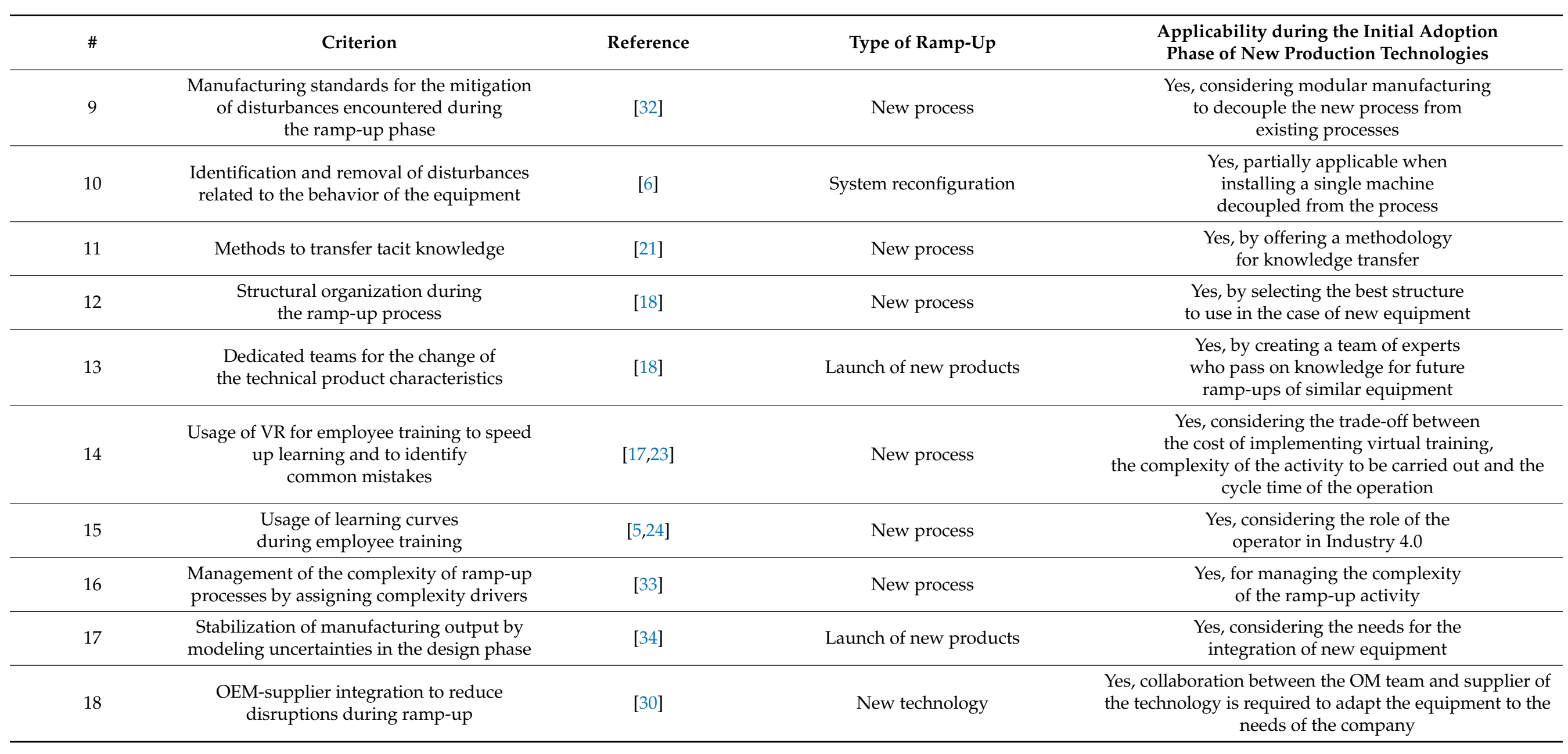




\section{Framework Proposal}

This paper aims to propose a comprehensive framework to evaluate the ramp-up phase of new production technologies by providing an evaluation methodology that highlights the critical aspects encountered during this period. Starting from the original TPM OEE definition [36], the paper introduces two different OEE calculation methodologies that allow distinctions to be made between human performance, process configuration and technical features of the production technology. In this context, if the causes of inefficiencies are not correctly identified, a risk of extension of the ramp-up period and a loss of additional TH can occur [29]. For this reason, the ramp-up phase is characterized by training of operators and managers, and, consequently, the classic definition of OEE should be adapted to differentiate between losses attributable to human and technical factors.

For this reason, our methodology provides two different OEE measurement methodologies by being able to compute the impact of human-process errors on the overall OEE value. This contribution has been obtained by considering the original OEE definition and providing a revised version, taking into account the abovementioned losses. Note that this has also been possible by performing a wide literature review on the methods to be applied to the ramp-up phase of new production technologies, whose applicability is discussed in the literature review section. Some assumptions are identified and adopted, which are described in the next subsections.

Moreover, by determining the possible losses, it has been possible to identify and introduce specific criteria for the target OEE calculation, whose objective is twofold. Firstly, these criteria allow managers to determine the moment in which the production technology is transitioning from the ramp-up state to the fully operational state. Secondly, they allow proper production capacity and workforce planning to be performed before entering the fully operational state of the machinery, considering both human and technical factors.

Lastly, the proposed framework and the OEE measurement methodologies have been discussed in relation to the ISO22400 OEE definition, to ensure the compatibility of the method with the international standard.

\subsection{Brief Recalls on TPM OEE}

To establish the foundation for the proposed OEE evaluation methodologies, brief recalls of the overall equipment effectiveness (OEE) are here reported. The OEE has been originally conceived and introduced within the contribution of Nakajima (1988) [36], to provide a methodology for the estimation of industrial equipment inefficiencies. This measurement has rapidly spread in the industrial and scientific context due to its ease of use and wide applicability [37-41], and it represents one of the leading manufacturing key performance indicators (KPIs).

The TPM OEE indicator is based on a time model which considers three main categories of inefficiencies-time losses, speed losses, and quality losses-which are in turn divided and classified into "six big losses" [36,42]. These losses are described and represented in the OEE time model in Figure 1 which is adapted from Nakajima's contribution [36,37]. The time model allows the different indicators that compose the OEE to be determined, namely: operating rate or availability $\left(\mathrm{OR}_{\mathrm{TPM}}\right)$, performance efficiency $\left(\mathrm{PE}_{\mathrm{TPM}}\right)$, and quality rate $\left(\mathrm{QR}_{\mathrm{TPM}}\right)$. From these considerations, the OEE calculation methodology is reported as in Table $2[36,37]$.

Table 2. Calculation of the TPM OEE.

\begin{tabular}{ccc}
\hline & \multicolumn{2}{c}{ TPM OEE Calculation Methodology } \\
\hline Operating rate/availability (ATPM) & $\mathrm{A}_{\mathrm{TPM}}=\frac{\mathrm{OPT}}{\mathrm{LT}}=\frac{\mathrm{LT}-\mathrm{DT}-\mathrm{LT}}{\mathrm{LT}}$ \\
Performance efficiency (PETPM) & $\mathrm{PE}_{\mathrm{TPM}}=\frac{\mathrm{NOT}}{\mathrm{OPT}}=\frac{\mathrm{OPT}-\mathrm{MST}-\mathrm{SLT}}{\mathrm{OPT}}$ & $(1)$ \\
Quality rate (QRTPM) & $\mathrm{QR}_{\mathrm{TPM}}=\frac{\mathrm{VOT}}{\mathrm{NOT}}=\frac{\mathrm{NOT}-\mathrm{DPT}-\mathrm{RWT}}{\mathrm{NOT}}$ & $(3)$ \\
OEETPM & $\mathrm{OEE}_{\mathrm{TPM}}=\mathrm{A}_{\mathrm{TPM}} \times \mathrm{PE}_{\mathrm{TPM}} \times \mathrm{QR}_{\mathrm{TPM}}$ \\
\hline
\end{tabular}




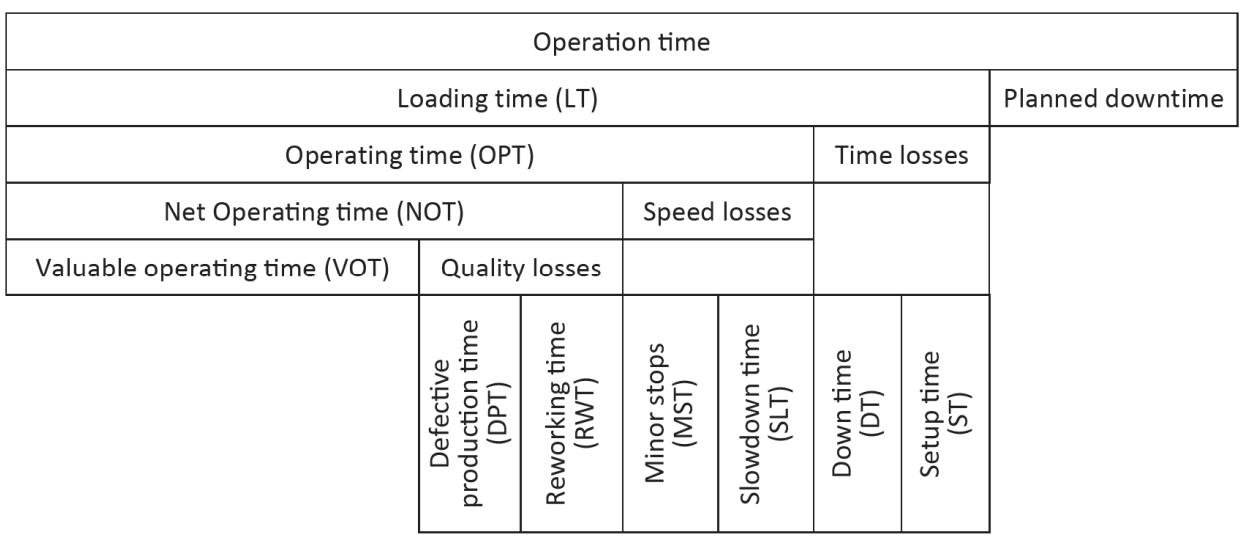

Figure 1. Representation of the OEE time model from Schiraldi and Varisco (2020) [37].

\subsection{Proposal of the OEE Measurement Methodologies}

This subsection introduces two different OEE measurement methodologies which allow distinctions to be made between human and technical factors. Both methodologies originate from the TPM OEE and can therefore be easily traced back to the framework reported in Table 2.

In addition, it should be highlighted that the methodology aims at differentiating the technical factors from the human factors, namely human errors and process configuration errors that can be traced back to the human activities. In this way, it would be possible to effectively consider the gap between technical performances and human performances, and to identify potential improvements for the ramp-up period.

Note that the proposed measurement framework strictly requires the possibility of implementing a data tracking platform in a digital and interconnected industrial environment. Indeed, the platform must track all the relevant parameters for the OEE calculation: operating time; downtime events and the time taken for recovery; and the count of compliant, non-compliant and processed products. The fundamental requirement of the data monitoring platform is to accurately track the flow of raw materials within the plant and the process, recording every type of physical movement and temporal duration of the materials. Moreover, it is assumed that the data tracking platform is able to distinguish between errors due to human activity or due to the machinery product processing. Without this digital platform and environment, it would not be possible to adopt the proposed framework.

Table 3 shows the definition of the metrics used in the OEE evaluation methodology. From the previous definitions, it is possible to obtain the following metrics, which will be adopted for the OEE calculation:

$$
\begin{gathered}
\text { Uptime }=\mathrm{PT}+\mathrm{IT}+\mathrm{BT}+\mathrm{ST} \\
\text { Downtime }=\mathrm{F}_{\mathrm{proc}}+\mathrm{F}_{\mathrm{mac}}+\mathrm{OM}+\mathrm{ST} \\
\text { Non }- \text { compliant products }=\mathrm{P}_{\mathrm{nc}}=\mathrm{P}_{\mathrm{nc}, \mathrm{proc}}+\mathrm{P}_{\mathrm{nc}, \mathrm{mac}} \\
\text { Potential products }=\mathrm{P}_{\text {pot }}=\mathrm{P}_{\mathrm{pot}, \text { proc }}+\mathrm{P}_{\mathrm{pot}, \mathrm{mac}} \\
\text { Target products }=\mathrm{P}_{\text {target }}=\mathrm{P}_{\mathrm{c}}+\mathrm{P}_{\mathrm{nc}}+\mathrm{P}_{\mathrm{pot}}
\end{gathered}
$$

where it is possible to observe that, considering a constant machine processing time (constant machine cycle time; expressed as CT), the following equivalency is obtained:

$$
\text { Uptime }=\mathrm{CT} \cdot \mathrm{P}_{\text {target }}=\mathrm{CT} \cdot\left(\mathrm{P}_{\mathrm{c}}+\mathrm{P}_{\mathrm{nc}}+\mathrm{P}_{\mathrm{pot}}\right)
$$


Table 3. Definition of metrics used for the OEE evaluation methodology.

\begin{tabular}{|c|c|}
\hline Parameter & Definition \\
\hline Production time (PT) & Sum of all the machine processing times \\
\hline Idle time (IT) & Unplanned machine minor stops and slowdown times \\
\hline Blocking time (BT) & $\begin{array}{l}\text { Unplanned stop time due to a block of the } \\
\text { downstream operations sequence }\end{array}$ \\
\hline Starving time (ST) & Unplanned stop time due to a lack of materials \\
\hline Faulted time due to the process (Fproc) & $\begin{array}{l}\text { Sum of all the major stops attributable to human errors } \\
\text { or to process configuration errors }\end{array}$ \\
\hline Faulted time due to the machinery (Fmac) & Sum of all the major stops attributable to the machinery errors \\
\hline Operator maintenance (OM) & Unplanned time in which the operator performs maintenance \\
\hline Setup time (ST) & Sum of time for setups and changeovers \\
\hline Non-compliant products due to the process $\left(\mathrm{P}_{\mathrm{nc}}\right.$, proc $)$ & $\begin{array}{l}\text { Number of products that need rework due to human } \\
\text { error or due to process configuration }\end{array}$ \\
\hline Non-compliant products due to the machinery $\left(\mathrm{P}_{\mathrm{nc}, \mathrm{mac}}\right)$ & Number of products that need rework due to machinery errors \\
\hline Potential products due to the process ( $\left.\mathrm{P}_{\text {pot, proc }}\right)$ & $\begin{array}{l}\text { Number of additional obtainable products in a fully } \\
\text { operational state with the absence of human-process errors }\end{array}$ \\
\hline Potential product due to the machinery $\left(\mathrm{P}_{\mathrm{pot}, \mathrm{mac}}\right)$ & $\begin{array}{l}\text { Number of additional obtainable products in a fully } \\
\text { operational state with the absence of machine errors }\end{array}$ \\
\hline Uptime (U) & Sum of production time, idle time, blocking time and starving time \\
\hline Downtime (D) & Sum of faulted time, operator maintenance and setup time \\
\hline Compliant products $\left(\mathrm{P}_{\mathrm{c}}\right)$ & Number of products that do not need reworking \\
\hline Non-compliant products $\left(\mathrm{P}_{\mathrm{nc}}\right)$ & $\begin{array}{l}\text { Number of products that need reworking, either for } \\
\text { human-process errors or for machinery errors }\end{array}$ \\
\hline Potential products $\left(\mathrm{P}_{\text {pot }}\right)$ & $\begin{array}{l}\text { Sum of additional obtainable products in a fully operational state } \\
\text { with the absence of human-process and machinery errors }\end{array}$ \\
\hline Target products $\left(\mathrm{P}_{\text {target }}\right)$ & $\begin{array}{l}\text { Sum of compliant products, non-compliant products } \\
\text { and potential products }\end{array}$ \\
\hline
\end{tabular}

Table 4 represents the OEE assessment methodologies, where considers all the inefficiencies that may occur during the production phase (namely inefficiencies due to the machinery, process configuration or human errors) and where considers only the inefficiencies due to the machinery, excluding the ones attributable to process configuration or human errors. Note that both calculation methodologies assume constant processing times (constant cycle times) and the possibility to implement a tracking platform, while the following assumptions are provided for the calculation:

- All the inefficiencies and time lost due to process configuration or human errors are considered as additional processing time for the machinery;

- During the additional processing time, no machinery losses are present;

- All products obtained in the additional processing time are compliant. 
Table 4. Representation of the OEE measurement methodologies, distinguishing between human and technical factors.

\begin{tabular}{|c|c|c|c|c|}
\hline & OEE Process Calculation & & OEE Machinery Calculation & \\
\hline Downtime (D) & $\mathrm{D}_{\text {proc }}=\mathrm{D}$ & $(11)$ & $\mathrm{D}_{\mathrm{mac}}=\mathrm{D}_{\text {proc }}-\mathrm{F}_{\text {proc }}$ & $(12)$ \\
\hline $\begin{array}{l}\text { Operating } \\
\text { rate/Availability (A) }\end{array}$ & $A_{\text {proc }}=\frac{U}{U+D_{\text {proc }}}$ & (13) & $\mathrm{A}_{\mathrm{mac}}=\frac{\mathrm{U}}{\mathrm{U}+\mathrm{D}_{\mathrm{mac}}}$ & (14) \\
\hline $\begin{array}{l}\text { Performance efficiency } \\
\text { (PE) }\end{array}$ & $\mathrm{PE}_{\text {proc }}=\frac{\mathrm{P}_{\mathrm{c}}+\mathrm{P}_{\mathrm{nc}}}{\mathrm{P}_{\text {target }}}$ & $(15)$ & $\mathrm{PE}_{\mathrm{mac}}=\frac{\mathrm{P}_{\mathrm{c}}+\mathrm{P}_{\mathrm{nc}}+\mathrm{P}_{\mathrm{Pot} \text { proc }}}{\mathrm{P}_{\text {target }}}$ & (16) \\
\hline Quality rate $(\mathrm{QR})$ & $\mathrm{QR}_{\text {proc }}=\frac{\mathrm{P}_{\mathrm{c}}}{\mathrm{P}_{\mathrm{c}}+\mathrm{P}_{\mathrm{nc}}}$ & (17) & $\mathrm{QR}_{\mathrm{mac}}=\frac{\mathrm{P}_{\mathrm{c}}+\mathrm{P}_{\mathrm{nc}, \mathrm{proc}}+\mathrm{P}_{\mathrm{Pot}, \text { proc }}}{\mathrm{P}_{\mathrm{c}}+\mathrm{P}_{\mathrm{nc}+} \mathrm{P}_{\mathrm{Pot}, \text { proc }}}$ & $(18)$ \\
\hline OEE & $\mathrm{OEE}_{\text {proc }}=\mathrm{A}_{\text {proc }} \cdot \mathrm{PE}_{\text {proc }} \cdot \mathrm{QR}_{\text {proc }}$ & $(19)$ & $\mathrm{OEE}_{\mathrm{mac}}=\mathrm{A}_{\mathrm{mac}} \cdot \mathrm{PE}_{\mathrm{mac}} \cdot \mathrm{QR}_{\mathrm{mac}}$ & $(20)$ \\
\hline
\end{tabular}

In light of these assumptions, it is possible to observe that the measurement methodology is derived from the calculation through the elimination of human-process inefficiencies.

Considering the previous table, it is clear that $\mathrm{OEE}_{\text {proc }}$ evaluates all possible inefficiencies, including human errors, process configuration errors and losses attributable to the machinery. Differently, $\mathrm{OEE}_{\mathrm{mac}}$ separates and recovers the factors attributable to an incorrect configuration of the process and human errors as additional processing times. The differentiation of the OEE measurement methodologies allows the real inefficiencies of the production technology to be isolated, assuming that human errors and process configuration errors are avoided. For this reason, the $\mathrm{OEE}_{\mathrm{mac}}$ value is always greater than the $\mathrm{OEE}_{\text {proc }}$ value.

Note that the added value of these measurement methodologies lies in the distinction between the losses of efficiency caused by human-process configuration errors and the ones caused by the machinery errors. This is obtained by the inclusion of potential products $\left(\mathrm{P}_{\text {pot }}\right)$ and in the distinction between non-compliant products due to human-process errors $\left(P_{n c, p r o c}\right)$ and non-compliant products due to machinery errors $\left(P_{n c, ~ m a c}\right)$ within the OEE assessment, as well as the distinction between downtime due to human-process errors $\left(\mathrm{F}_{\text {proc }}\right)$ and due to machinery errors $\left(\mathrm{F}_{\mathrm{mac}}\right)$.

\subsection{Criteria for Target OEE Calculation}

Production and workforce capacity planning is usually performed ahead of the end of the ramp-up period to anticipate the needs of the fully operational state of the technology. Moreover, organizations should be able to estimate and determine the conditions under which the transition from the ramp-up phase to the fully operational state is obtained. In this context, the OEE measurement could be employed to forecast the expected processable quantity for the fully operational state of the production technology, since this measurement is suitable for automatic and semi-automatic production processes [43]. However, the OEE calculation should also consider the impact of the human aspects (e.g., training) that influence the duration of the ramp-up phase.

For this reason, starting from the proposed OEE measurement methodologies, a set of criteria is here introduced to evaluate and perform proper production planning and to establish the moment in which the ramp-up state is over. The following criteria are proposed for the estimation of the target OEE to be obtained in the fully operational state of the production technology:

1. Compute the actual OEE value of the machinery $\left(\mathrm{OEE}_{\mathrm{mac}}\right)$ : it is required to compute the OEE value that filters the components due to human and process configuration errors occurring during the adoption phase of new production technologies to obtain the actual machinery OEE value. For this calculation, refer to Section 3.2. It is hence assumed that the human-process losses do not occur in a fully operational state, or that they occur in a less systematic manner;

2. Evaluate the average OEE during the ramp-up phase;

3. Evaluate the percentage of OEE which increases due to completion of trainings: this value can be computed by considering the percentage of OEE increase obtained 
between the end and the beginning of the training. It is therefore possible to indicate the value as in Equation (21):

$$
\Delta \mathrm{OEE}_{\text {training }}=\frac{\mathrm{OEE}_{\text {post-training }}}{\mathrm{OEE}_{\text {average, ante-post }}}-1
$$

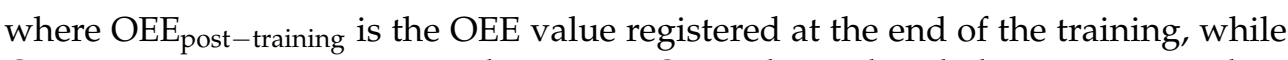
$\mathrm{OEE}_{\text {average, ante-post }}$ represents the average OEE value in the whole training period. In addition, if different groups of people are trained, it is possible to obtain the average percentage of OEE increase due to trainings completion as in Equation (22):

$$
\Delta \mathrm{OEE}_{\text {average, training }}=\frac{\sum \Delta \mathrm{OEE}_{\text {training }}}{\text { Number of groups }}
$$

Note that this calculation obtains the increase in OEE which is exclusively due to operator training, which is assumed to be achieved at the start of the production technology fully operational state;

4. Evaluate the decrease of "Mean Time To Repair" (MTTR) of the regular maintenance operations carried out by the operators: it is assumed that in a fully operational state-when the learning process of operators is completed - the operators will be able to manage the machinery alarms in a shorter time interval, leading to an increase in availability. In the absence of recorded data for MTTR evaluation, the availability of the machine can be assessed by considering the downtime in a fully operational state, when it can be estimated that no downtime will be caused due to incorrect maintenance procedures that may occur during the ramp-up phase. For this reason, it is required to estimate the fully operational downtime as in Equation (23) and the fully operational availability as in Equation (24):

$$
\begin{gathered}
D_{\text {mac, fully operational }}=D_{\text {mac }}-D_{\text {reduced maintenance }} \\
A_{\text {mac fully operational }}=\frac{U}{U+D_{\text {mac, fully operational }}}
\end{gathered}
$$

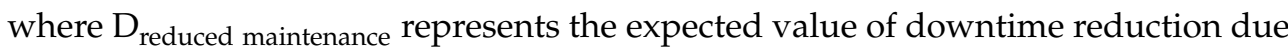
to the decrease in regular maintenance operations, MTTR. Note that once the fully operational availability has been computed, it is possible to provide the re-evaluated value of the machinery OEE as follows:

$$
\mathrm{OEE}_{\mathrm{mac}_{\text {re-evaluated }}}=\mathrm{A}_{\text {mac fully operational }} \cdot \mathrm{PE}_{\mathrm{mac}} \cdot \mathrm{QR}_{\mathrm{mac}}
$$

5. Compute the expected OEE value for the fully operational state of the production technology and estimate the number of additional processable products: once all of the previous criteria have been applied, Equation (26) shows how to compute the target OEE:

$$
\begin{gathered}
\mathrm{OEE}_{\text {target }}=\mathrm{OEE}_{\mathrm{mac}_{\text {re-evaluated }}} \cdot\left(1+\Delta \mathrm{OEE}_{\text {average, training }}\right)= \\
=\left(\mathrm{A}_{\text {mac }}\right. \text { fully operational } \\
\left.\mathrm{PE}_{\mathrm{mac}} \cdot \mathrm{QR}_{\text {mac }}\right) \cdot\left(1+\Delta \mathrm{OEE}_{\text {average, training }}\right)
\end{gathered}
$$

Note that this methodology allows the target OEE value for the fully operational state of the considered production technology to be computer, and therefore estimates the period in which the ramp-up phase ends. Indeed, once the training periods are completed and the production technology performances steadily achieve the target OEE value, it is possible to establish the conclusion of the ramp-up period. 


\subsection{OEE Evaluation Methodology and ISO22400 Standard}

The ISO22400 represents the international standard published by the "International Organization for Standardization" (ISO) with the aim of defining, harmonizing and standardizing key performance indicators (KPIs) for manufacturing operations management [44,45]. This standard has recently gained a rising interest in both the industrial and scientific environments [37,46-48] due to its practical and wide applicability to the manufacturing field. The standard provides relevant KPIs for different activities within the context of manufacturing operations management, and specifically it defines two different methods of computing the OEE, which can be traced back to the original TPM OEE definition [37]. The detailed definition of the ISO22400 OEE indicators is provided in the ISO standard (2014) [45] and in the contribution of Schiraldi and Varisco (2020) [37].

In this context, due to the growing interest towards the application of the ISO22400 standard, this section shows the relationships between the metrics and losses of efficiency that have been introduced in Table 3 Indeed, the definition of a link between the proposed framework and the ISO22400 standard could help researchers and practitioners move toward the correct application of the provided OEE measurement methodologies. For this reason, starting from the contribution of Schiraldi and Varisco (2020) [37], which indicates the equipment state to be considered for the ISO22400 OEE computation, in what follows the correspondence between proposed metrics and the possible equipment states classification is provided.

Table 5 shows the equipment states that can be related to the specific parameters introduced by Section 3.2. The table correlates the specific metrics of the proposed framework with the equipment state, which leads to the time elements of the ISO22400 standard they are referred to [37]. Hence, this classification matches the proposed OEE measurement methodologies with the ISO22400 OEE indicators and establishes a connection for performing an effective implementation of the standard.

Table 5. Correspondence between the proposed metrics and the equipment states proposed by Schiraldi \& Varisco (2020) [37].

\begin{tabular}{lll}
\hline Parameter & Related Equipment State & Specification \\
\hline Production time (PT) & ON & Run \\
Idle time (IT) & SLOW & Stopped for delays; reduced speed \\
Blocking time (BT) & STOP & Blocking \\
Starving time $(\mathrm{ST})$ & STOP & Starvation \\
Faulted time due to the process (Fproc) & STOP/OFF & Unplanned switch off \\
Faulted time due to the machinery (Fmac) & STOP/OFF & Unplanned switch off \\
Operator maintenance $(\mathrm{OM})$ & STOP & Unplanned switch off \\
Setup time $(\mathrm{ST})$ & STOP & Setup \\
Non-compliant products due to the process $\left(\mathrm{P}_{\mathrm{nc}}, \mathrm{proc}\right)$ & ON & Run \\
Non-compliant products due to the machinery $\left(\mathrm{P}_{\mathrm{nc}}, \mathrm{mac}\right)$ & ON & Run \\
Potential products due to the process $\left(\mathrm{P}_{\text {pot, }}\right.$ proc & SLOW & Stopped for delays; reduced speed \\
Potential product due to the machinery $\left(\mathrm{P}_{\text {pot, } \mathrm{mac}}\right)$ & SLOW & Stopped for delays; reduced speed \\
Uptime $(\mathrm{U})$ & ON & Run \\
Downtime $(\mathrm{D})$ & STOP/OFF & Unplanned switch off; blocking; \\
Compliant products $\left(\mathrm{P}_{\mathrm{c}}\right)$ & ON & starvation \\
Non-compliant products $\left(\mathrm{P}_{\mathrm{nc}}\right)$ & ON & Run \\
Potential products $\left(\mathrm{P}_{\text {pot }}\right)$ & SLOW & Run \\
Target products $\left(\mathrm{P}_{\text {target }}\right)$ & ON & Stopped for delays; reduced speed \\
\hline
\end{tabular}

\section{Case Study of a Semi-Automatic Packaging Machine in a Logistics Company}

The case study examines the adoption phase of a new technology for a B2C company in the logistics sector that interfaces with consumers through e-commerce. Specifically, the integration of a semi-automatic packaging machine that produces parcels intended for small objects in outbound operations is studied. The raw materials employed by the 
machine are paper, glue and inkjet. The machine was originally intended for the packaging of parcels with constant dimensions, considering little variability in size, such as covers and documents, and it has been adapted for the packaging of objects of variable though limited size. Following the machine reconfiguration, no historical metrics relating to the processing procedures and technology performance were present.

The human figure role is here linked to the insertion of products on the machine's feeding belt after scanning the objects, and to the management of production stops through the human-machine interface. Operators must also manage machine downtime events and start-ups following downtimes.

The infeed belt is divided into slots highlighted by colored markers, and the objects must be inserted in the available slots, otherwise the items will be discarded from the machine upon entry. Moreover, the machine has the following features:

- The technology has a minimum operating speed and a maximum speed; at the beginning of production, the operating speed has to be set according to the planned hourly units and according to the number of operators employed in the process. Following the start-up, the technology operates at a constant capacity and does not automatically adjust the speed of packages productions to the infeed rate of operators;

- For each empty slot on the infeed belt, an empty package is produced. Therefore, all slots on the feeder belt must be filled, so as to not produce paper waste in the form of empty packages;

- The technology registers the position of the items inserted in the slot after the article is scanned by the operator and positioned on the belt. At the entrance of the packaging module, the position of the object is checked using sensors; if there are no belt position variations, the object continues towards the packaging operations. Otherwise, it is discarded in a waste trolley. Objects that do not comply with the dimensions required by the machine are also rejected;

- The machine also has a second reject trolley for non-compliant packages. Initially, the machine was tested with the support of the supplier. Once the processing procedures were defined, the company employed its operators in the process, which resulted in a machine performance decrease.

In what follows, the proposed methodology is applied to and validated through the described case study. Firstly, a description of the OEE measurement methodologies is provided in relation to the specific features of the case study. Then, results of the applied methodology are reported and discussed. Note that for confidentiality purposes data are not shown in this contribution; hence Section 4.2 shows only the data trend for the proposed metrics.

\subsection{OEE Definition: Semi-Automatic Packaging Machine}

The previously described OEE measurement methodologies can be applied to several typologies of production technologies through an adaptation of the different metrics. Indeed, the factors to be considered for the OEE evaluation vary according to the type of machinery and the kind of inefficiency typically encountered in the production start-up phase. To give a practical overview of the proposed OEE indicators, they are here adapted and applied to the described case study. Table 6 shows the specific parameters which have been adopted in the OEE evaluation. Note that this application can be performed for different types of machines to obtain relevant OEE measurements.

Considering the "not scanned products" $\left(\mathrm{P}_{\text {no, scan }}\right)$, these can be observed when the technology requires operators to scan a product identification code prior to processing which is either not performed by error or incorrectly performed. Differently, the "not loaded products" $\left(\mathrm{P}_{\text {no load }}\right)$ consist of all the semi-finished products or raw materials that are transported to the machinery and yet not processed by the operators, even though they have been considered processable by the information system. This may happen when the operators conduct an inspection of the technical and physical characteristics of the items and decide that they are not compliant with the technology's processing conditions. 
For this reason, this operator's choice must be considered as a loss of efficiency due to a human error. In addition, the "empty packages" $\left(\mathrm{P}_{\text {empty }}\right)$ are defined as the number of void packages due to the constant operating speed of the machine, which is not adapted to the processing rate of the operators. Hence, this loss must be assumed as an intrinsic loss of efficiency caused by the machinery.

Table 6. Definition of metrics used for the OEE evaluation methodology for a semi-automatic packaging machine.

\begin{tabular}{ll}
\hline Parameters & Specific Definition \\
\hline Not scanned products $\left(\mathrm{P}_{\text {no scan }}\right)$ & Number of products not scanned correctly by operators \\
Not loaded products $\left(\mathrm{P}_{\text {no load }}\right)$ & $\begin{array}{l}\text { Number of products that are inspected by operators, } \\
\text { but that are not processed }\end{array}$ \\
Empty packages $\left(\mathrm{P}_{\mathrm{empty}}\right)$ & $\begin{array}{l}\text { Number of empty packages caused by the constant production speed of } \\
\text { the machinery }\end{array}$ \\
\hline
\end{tabular}

These considerations lead to the following definition of potential products and target products for the semi-automatic packaging machine:

$$
\begin{gathered}
\mathrm{P}_{\text {pot, proc }}=\mathrm{P}_{\text {no scan }}+\mathrm{P}_{\text {no load }} \\
\mathrm{P}_{\text {pot, mac }}=\mathrm{P}_{\text {empty }}
\end{gathered}
$$

$$
\begin{gathered}
\text { Potential products }=\mathrm{P}_{\text {pot }}=\mathrm{P}_{\text {pot, process }}+\mathrm{P}_{\text {pot, mac }}=\mathrm{P}_{\text {no scan }}+\mathrm{P}_{\text {no load }}+\mathrm{P}_{\text {empty }} \\
\text { Target products }=\mathrm{P}_{\text {target }}=\mathrm{P}_{\mathrm{c}}+\mathrm{P}_{\mathrm{nc}}+\mathrm{P}_{\text {no scan }}+\mathrm{P}_{\text {no load }}+\mathrm{P}_{\text {empty }}
\end{gathered}
$$

Therefore, in this case, the only loss of performance efficiency for the OEE process is given by the "empty packages" ( $\left.\mathrm{P}_{\text {empty }}\right)$. Indeed, as already mentioned, this loss is encountered for technologies that operate at a constant operative speed without adapting the production capacity to the processing rate of the operators.

\subsection{Results and Discussion}

Figures $2-5$ provide, respectively, the data trend for the process and machine OEE, availability, performance efficiency and quality rate. Note that only the data trends for a period of 20 days are shown for confidentiality purposes, and no absolute values are reported and described. Moreover, in the different figures, the dashed curves show the performance recorded during the controlled tests conducted by the machine's supplier technicians, while the continuous curves record the performances following the employment of the company's operators for production.

From these data, it is possible to observe a $11 \%$ increase in $\mathrm{OEE}_{\mathrm{mac}}$ and a $18 \%$ increase in $\mathrm{OEE}_{\text {proc }}$ from day 13 to day 20. This OEE increase gap could be due to the operator training process: during this timeframe, operator training was sped up, resulting in lower human-process inefficiencies. Indeed, following the employment of the company's operators for production (day 10) and the variability of day 11-12, the company decided to intensify the operator training process.

A similar pattern is observed also for availability, performance efficiency and quality rate. Moreover, specifically for the availability, $A_{\text {mac }}$ and $A_{\text {proc }}$ obtained the same values during day 18 , meaning that no human-process inefficiency has occurred in that specific day. This result has been possible due to an intensification of the operator training process, with a major focus on the faulted time due to operator errors (e.g., operators were frequently placing items with non-allowed dimensions on the infeed belt, generating downtimes). Additionally, considering performance efficiency and quality rate, the distance between machine and process values steadily decreased during the operator training period due to the possibility to evaluate the human-process inefficiencies with the proposed framework. 


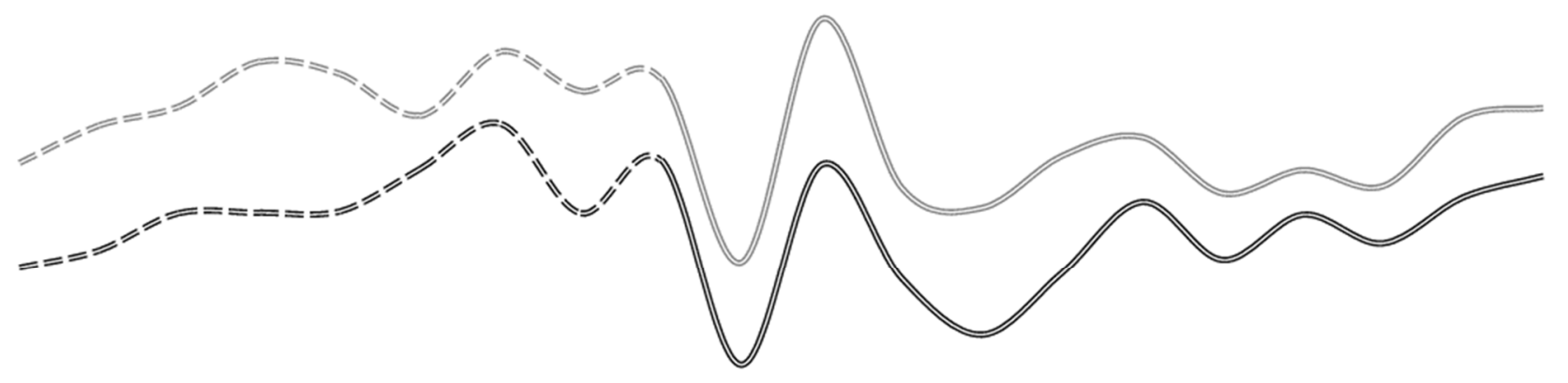

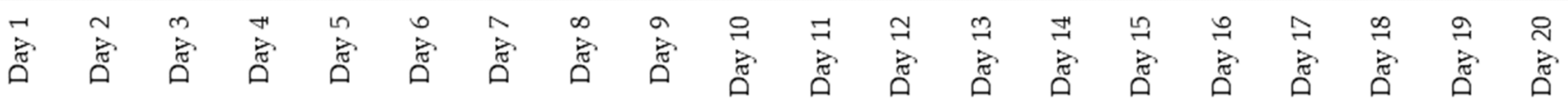
Process $=$ Machine

Figure 2. OEE trend for the semi-automatic packaging machine.

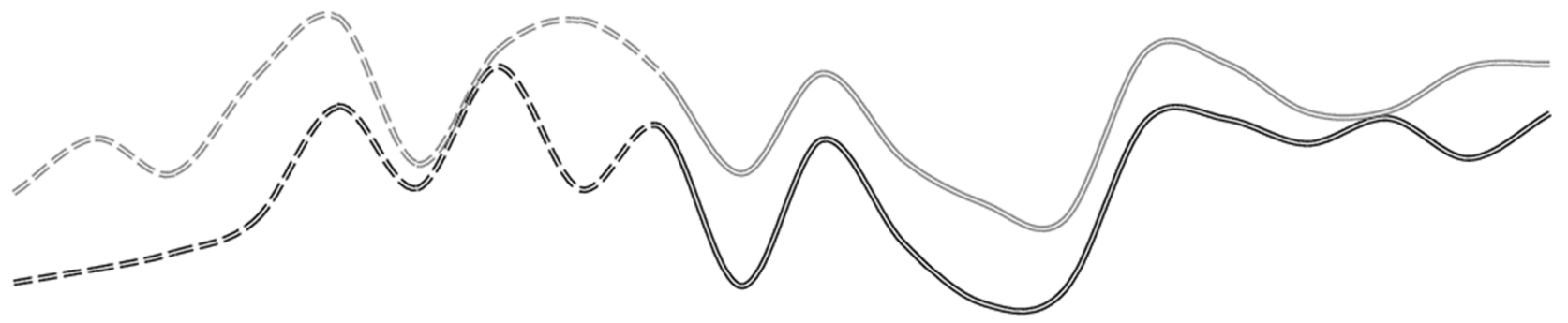

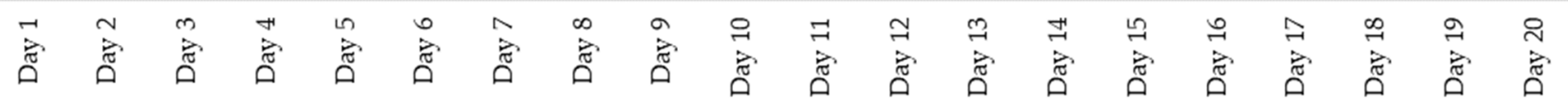
Process $=$ Machine

Figure 3. Operating rate/availability trend for the semi-automatic packaging machine.

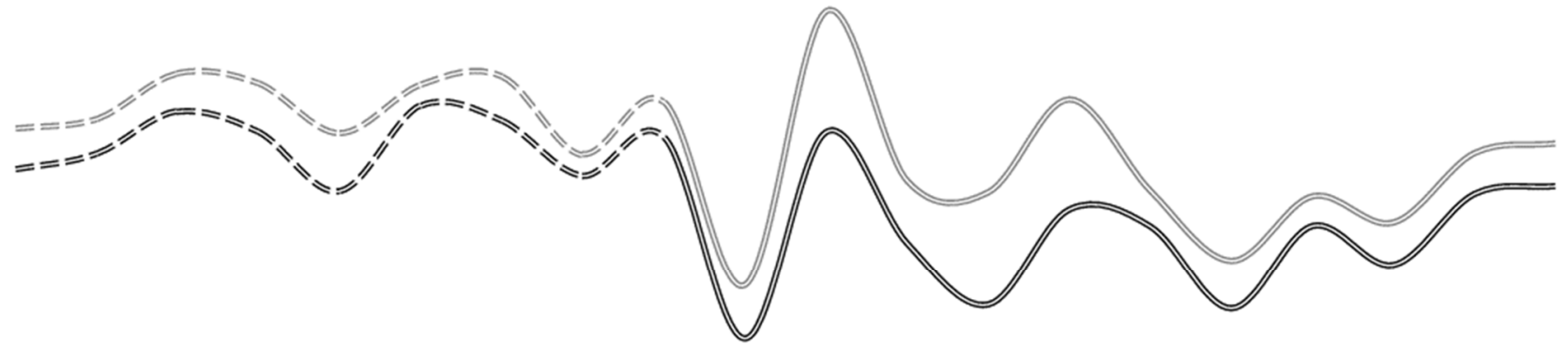

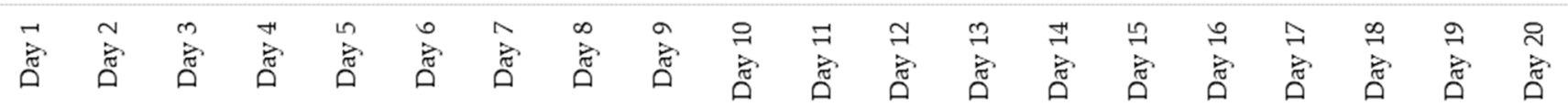
Process $=$ Machine

Figure 4. Performance efficiency trend for the semi-automatic packaging machine. 


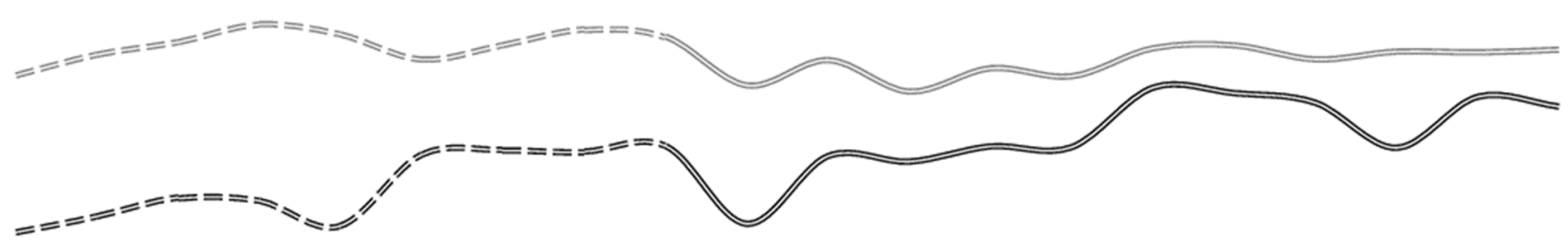

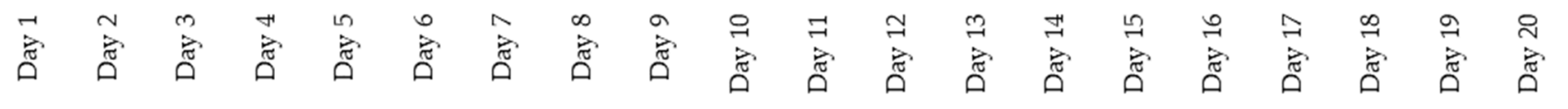 Process $=$ Machine}

Figure 5. Quality rate trend for the semi-automatic packaging machine.

Successively, the target OEE value has been calculated according to the proposed criteria described in Section 3.3; this allowed the moment in which the ramp-up state was over to be determined and for proper production and workforce planning to be performed. Once again, it has not been possible to report the computed value for confidentiality purposes. In conclusion, this case study allowed the testing and validation of the proposed OEE measurement methodologies and the criteria for target OEE calculation. It also allowed the provision of valuable insights for improving the adoption of the new semi-automatic packaging machine and for reducing the overall length of the ramp-up period.

\section{Conclusions}

This paper discusses the factors that impact the ramp-up phase of new production technologies and proposes a framework to evaluate the machinery performances in a digital and interconnected environment by distinguishing between human and technological factors. Specifically, the paper analyzes models and criteria for the ramp-up phase of new products, new processes and system reconfigurations, and provides an indication of their applicability to the introduction of new production technologies. Moreover, a comprehensive framework to evaluate the production technology performance is proposed.

The framework is composed of two different OEE measurement methodologies that distinguish between human-technological factors, as well as a set of criteria that allow for the estimation and determination of the conditions under which the transition from the ramp-up phase to the fully operational state is obtained. Secondarily, this methodology could also be adopted to perform proper production and workforce capacity planning ahead of the ramp-up period conclusion. Successively, the metrics and definition provided in this contribution are analyzed in relation to the equipment state classification of Schiraldi and Varisco (2020) [37], which leads to a matching of the proposed OEE with the ISO22400 OEE measurement methodologies.

It should be noted that, to perform this calculation, it is assumed that the inefficiencies and time lost due to process configurations or human errors are considered as additional processing time for the machinery. Moreover, during the additional processing times, only compliant products are manufactured, without any machinery loss. These strong assumptions are required to effectively estimate the impact of the process configuration or human errors on the overall OEE value and to obtain insights and continuous improvement for the achievement of stable production output.

It should be observed that the proposed framework strictly requires the implementation of a data tracking platform in a digital and interconnected industrial environment. Indeed, the platform must track all relevant parameters for the OEE calculation, so that it will be possible to effectively distinguish between human performance, process configuration and technical features of the production technology. Hence, the fundamental requirement of the data monitoring platform is to accurately track the flow of raw materials within the plant and the process, recording every type of physical movement and 
temporal duration of the materials. Indeed, without the presence of a digital platform and environment, the proposed methodology would become unapplicable.

Additionally, the proposed framework is applied to a case study concerning the introduction of a semi-automatic packaging machine in a relevant multinational logistics company. The case study allowed the framework to be assessed and validated by studying the semi-automatic packaging machine ramp-up period and provided insights for its optimization. In the future, further applications of this research work could be carried out to determine its validity in different sectors and to model the OEE measurement methodologies accordingly. Moreover, an additional development of this methodology could be given by coupling with continuous improvement techniques (e.g., the Kaizen technique) to reduce the identified inefficiencies and errors.

Author Contributions: Conceptualization, S.D.L.; data curation, G.R.P.; formal analysis, G.R.P.; investigation, S.D.L.; methodology, M.M.S.; project administration, S.D.L.; supervision, M.M.S.; validation, G.R.P.; writing — original draft, S.D.L. and G.R.P.; writing-review \& editing, S.D.L. and M.M.S. All authors have read and agreed to the published version of the manuscript.

Funding: This research received no external funding.

Institutional Review Board Statement: Not applicable.

Informed Consent Statement: Not applicable.

Conflicts of Interest: The authors declare no conflict of interest.

\section{References}

1. Terwiesch, C.; Bohn, R.E. Learning and process improvement during production ramp-up. Int. J. Prod. Econ. 2001, 70, 1-19. [CrossRef]

2. Doltsinis, S.; Ferreira, P.; Mabkhot, M.M.; Lohse, N. A Decision Support System for rapid ramp-up of industry 4.0 enabled production systems. Comput. Ind. 2020, 116, 103190. [CrossRef]

3. Kim, T.; Glock, C.H.; Emde, S. Production planning for a ramp-up process in a multi-stage production system with worker learning and growth in demand. Int. J. Prod. Res. 2020. [CrossRef]

4. Basse, I.; Schmitt, S.; Gartzen, T.; Schmitt, R. Solution principles for managing instabilities in ramp-up. Procedia Cirp 2014, 20, 93-97. [CrossRef]

5. Glock, C.H.; Jaber, M.Y.; Zolfaghari, S. Production planning for a ramp-up process with learning in production and growth in demand. Int. J. Prod. Res. 2020, 50, 5707-5718. [CrossRef]

6. Colledani, M.; Tolio, T.; Yemane, A. Production quality improvement during manufacturing systems ramp-up. CIRP J. Manuf. Sci. Technol. 2018, 23, 197-206. [CrossRef]

7. Hansen, K.R.; Grunow, M. Modelling ramp-up curves to reflect learning: Improving capacity planning in secondary pharmaceutical production. Int. J. Prod. Res. 2015, 53, 99-5417. [CrossRef]

8. Dalenogare, L.S.; Benitez, G.B.; Ayala, N.F.; Frank, A.G. The expected contribution of Industry 4.0 technologies for industrial performance. Int. J. Prod. Econ. 2018, 204, 383-394. [CrossRef]

9. Jeske, T.; Weber, M.A.; Würfels, M.; Lennings, F.; Stowasser, S. Opportunities of digitalization for productivity management. In Proceedings of the International Conference on Applied Human Factors and Ergonomics, Orlando, FL, USA, 22-26 July 2018; pp. 321-331.

10. Jeske, T.; Würfels, M.; Lennings, F.; Weber, M.A.; Stowasser, S. Achievements and Opportunities of Digitalization in Productivity Management. In Proceedings of the International Conference on Applied Human Factors and Ergonomics, San Diego, CA, USA, 16-20 July 2020; pp. 17-24.

11. Cimini, C.; Lagorio, A.; Romero, D.; Cavalieri, S.; Stahre, J. Smart Logistics and The Logistics Operator 4.0. In Proceedings of the 21st IFAC World Congress, Berlin, Germany, 12-17 July 2020.

12. Nota, G.; Peluso, D.; Lazo, A.T. The contribution of Industry 4.0 technologies to facility management. Int. J. Eng. Bus. Manag. 2021, 13, 1-14. [CrossRef]

13. D'Orazio, L.; Messina, R.; Schiraldi, M.M. Industry 4.0 and World Class Manufacturing Integration: 100 Technologies for a WCM-I4.0 Matrix. Appl. Sci. 2020, 10, 4942. [CrossRef]

14. Alharbi, O. Industry 4.0 Operators: Core Knowledge and Skills. Adv. Sci. Technol. Eng. SystJ. 2020, 5, 177-183. [CrossRef]

15. Fantini, P.; Pinzone, M.; Taisch, M. Placing the operator at the centre of Industry 4.0 design: Modelling and assessing human activities within cyber-physical systems. Comput. Ind. Eng. 2020, 139, 105058. [CrossRef]

16. Silvestri, L.; Forcina, A.; Introna, V.; Santolamazza, A.; Cesarotti, V. Maintenance transformation through Industry 4.0 technologies: A systematic literature review. Comput. Ind. 2020, 123, 103335. [CrossRef] 
17. Ordaz, N.; Romero, D.; Gorecky, D.; Siller, H.R. Serious games and virtual simulator for automotive manufacturing education \& training. Procedia Comput. Sci. 2015, 75, 257-266.

18. Schmitt, R.; Heine, I.; Jiang, R.; Giedziella, F.; Basse, F.; Voet, H.; Lu, S. On the future of ramp-up management. CIRP J. Manuf. Sci. Technol. 2018, 23, 217-225. [CrossRef]

19. Tang, H. A new method of bottleneck analysis for manufacturing systems. Manuf. Lett. 2019, 19, 21-24. [CrossRef]

20. Argote, L.; Miron-Spektor, E. Organizational learning: From experience to knowledge. Organ. sci. 2011, 22, 1123-1137. [CrossRef]

21. Letmathe, P.; Rößler, M. Tacit knowledge transfer and spillover learning in ramp-ups. Int. J. Oper. Prod. Manag. 2019, 39, 1099-1121. [CrossRef]

22. Scholz-Reiter, B.; Krohne, F.; Leng, B.; Höhns, H. Technical product change teams: An organizational concept for increasing the efficiency and effectiveness of technical product changes during ramp-up phases. Int. J. Prod. Res. 2007, 45, 1632-1642. [CrossRef]

23. Hoedt, S.; Claeys, A.; Van Landeghem, H.; Cottyn, J. The evaluation of an elementary virtual training system for manual assembly. Int. J. Prod. Res. 2017, 55, 7496-7508. [CrossRef]

24. Ball, P.D.; Roberts, S.; Natalicchio, A.; Scorzafave, C. Modelling production ramp-up of engineering products. Proc. Inst. Mech. Eng. Part B J. Eng. Manuf. 2011, 225, 956-971. [CrossRef]

25. Wright, T.P. Factors affecting the cost of airplanes. J. Aeronaut. Sci. 1936, 3, 122-128. [CrossRef]

26. Manca, D.; Nazir, S.; Lucernoni, F.; Colombo, S. Performance indicators for the assessment of industrial operators. Comput. Aided Chem. Eng. 2012, 30, 1422-1426.

27. Reiman, A.; Kaivo-oja, J.; Parviainen, E.; Takala, E.P.; Lauraeus, T. Human factors and ergonomics in manufacturing in the industry 4.0 context-A scoping review. Technol. Soc. 2021, 65, 101572. [CrossRef]

28. Kadir, B.A.; Broberg, O.; da Conceicao, C.S. Current research and future perspectives on human factors and ergonomics in Industry 4.0. Comput. Ind. Eng. 2019, 137, 106004. [CrossRef]

29. Dombrowski, U.; Wullbrandt, J.; Krenkel, P. Industrie 4.0 in production ramp-up management. Procedia Manuf. 2018, 17, 1015-1022. [CrossRef]

30. Wlazlak, P.; Säfsten, K.; Hilletofth, P. Original equipment manufacturer (OEM)-supplier integration to prepare for production ramp-up. J. Manuf. Technol. Manag. 2019, 30, 506-530. [CrossRef]

31. Klocke, F.; Stauder, J.; Mattfeld, P.; Muller, J. Modeling of manufacturing technologies during ramp-up. Procedia Cirp 2016, 51, 122-127. [CrossRef]

32. Burggräf, P.; Dannapfel, M.; Voet, H. Potentials of facotry standards in production ramp-ups. Procedia Cirp 2016, 51, 134-139. [CrossRef]

33. Schuh, G.; Gartzen, T.; Wagner, J. Complexity-oriented ramp-up of assembly systems. CIRP J. Manuf. Sci. Technol. 2015, 10, 1-15. [CrossRef]

34. Kukulies, J.; Schmitt, R. Stabilizing production ramp-up by modeling uncertainty for product design verification using DempsterShafer theory. CIRP J. Manuf. Sci. Technol. 2018, 23, 187-196. [CrossRef]

35. Cheah, C.K.; Prakash, J.; Ong, K.S. An integrated OEE framework for structured productivity improvement in a semiconductor manufacturing facility. Int. J. Product. Perform. Manag. 2020, 69, 1081-1105. [CrossRef]

36. Nakajima, S. Introduction to TPM; Productivity Press: Portland, OR, USA, 1988.

37. Schiraldi, M.M.; Varisco, M. Overall Equipment Effectiveness: Consistency of ISO standard with literature. Comput. Ind. Eng. 2020, 145, 106518. [CrossRef]

38. Pasic, F.; Wohlers, B.; Dziwok, S.; Becker, M.; Heinrich, M. A KPI-based condition monitoring system for beer brewing process. In Proceedings of the 24th IEEE International Conference on Emerging Technologies and Factory Automation (ETFA), Zaragoza, Spain, 10-13 September 2019.

39. Iannone, R.; Nenni, M. Managing OEE to Optimize Factory Performance. In Operations Management; IntechOpen: London, UK, 2013; pp. 31-50.

40. Loaiza, R.E.P.; Olivares-Benitez, E.; Gonzalez, P.A.M.; Campanur, A.G.; Flores, J.L.M. Supply chain network design with efficiency, location, and inventory policy using a multiobjective evolutionary algorithm. Int. Trans. Oper. Res. 2016, 24, 251-275. [CrossRef]

41. Morales-García, A.S.; Díaz-Reza, J.R.; García-Alcaraz, J.L. Effect of TPM and OEE on the Social Performance of Companies. In New Perspectives on Enterprise Decision-Making Applying Artificial Intelligence Techniques; Springer: Berlin/Heidelberg, Germany, 2021; pp. 119-141.

42. Bamber, C.; Castka, P.; Sharp, J.; Motara, Y. Cross-functional team working for overall equipment effectiveness. J. Qual. Maint. Eng. 2003, 9, 223-238. [CrossRef]

43. Hedman, R.; Subramaniyan, M.; Almström, P. Analysis of critical factors for automatic measurement of OEE. Procedia Cirp 2016, 57, 128-133. [CrossRef]

44. ISO. ISO22400:1-Automation Systems and Integration-Key Performance Indicators (KPIs) for Manufacturing Operations ManagementPart. 1: Overview, Concepts and Terminology; International Organization for Standardization (ISO): Geneva Switzerland, 2014.

45. ISO. ISO22400:2 - Automation Systems and Integration-Key Performance Indicators (KPIs) for Manufacturing Operations ManagementPart. 2: Definitions and Descriptions; International Organization for Standardization (ISO): Geneva Switzerland, 2014.

46. Bauer, M.; Lucke, M.; Johnsson, C.; Harjunkoski, I.; Schlake, J.C. KPIs at the interface between scheduling and control. IFACPapersOnLine 2016, 49, 687-692. [CrossRef] 
47. Di Luozzo, S.; Varisco, M.; Schiraldi, M.M. The diffusion of international standards on managerial practices. Int. J. Eng. Bus. Manag. 2020, 12, 1-17. [CrossRef]

48. Ferrer, B.R.; Muhammad, U.; Mohammed, W.M.; Lastra, J.L.M. Implementing and visualizing ISO22400 key performance indicators for monitoring discrete manufacturing systems. Machines 2018, 6, 1-22. 